\title{
Influence of Vortex Structure on Fire Whirl Behavior
}

\author{
YASUHIRO HAYASHI ${ }^{1}$, KAZUNORI KUWANA ${ }^{2}$, and RITSU DOBASHI ${ }^{1}$ \\ ${ }^{1}$ School of Engineering \\ University of Tokyo \\ 7-3-1 Hongo, Bunkyo-ku, Tokyo 113-8656, Japan \\ ${ }^{2}$ School of Science and Engineering \\ Yamagata University \\ 4-3-16 Jonan, Yonezawa-shi, Yamagata 992-8510, Japan
}

\begin{abstract}
This paper reports the results of experimental investigations on laboratory-scale fire whirls. Fixed-frame type fire whirls of methanol pool were generated and tangential and radial velocity distributions near the flame base were measured. Changes in flame height and flame-base shape under three different flow conditions were compared in order to understand the relation between the flame height, vortex structure and the mechanism of flame height increase. It is proposed to use the parameter $a$, a measure of the degree of closeness of flame to liquid fuel based on the approximation of flame-base shape using a parabolic function, to correlate flame height; it was observed that the quantity $a$ had a certain relationship with the flame height. In addition, it was experimentally found that the radial velocity distribution near the flame base had a significant influence on the flame height because the radial inflow makes the flame shape thinner resulting in a concave flame shape near the base which increases the heat flux to the liquid surface, thereby increasing the evaporation rate of liquid fuel.
\end{abstract}

KEYWORDS: fire whirl, flame height, radial velocity.

\section{NOMENCLATURE LISTING}

$c \quad$ core radius of vortex $(\mathrm{cm})$

$\mathrm{Pe} \quad$ Peclet number

$r, z, \theta$ cylindrical coordinates

$r_{\mathrm{p}} \quad$ pool radius $(\mathrm{cm})$

$v_{\mathrm{i}} \quad$ velocity component $(\mathrm{m} / \mathrm{s})$

$Z_{\mathrm{st}} \quad$ stoichiometric value of mixture fraction

$z_{\mathrm{f}} \quad$ flame height $(\mathrm{cm})$

$z_{\mathrm{f} \infty} \quad$ flame height without spinning flow $(\mathrm{cm})$

a degree of closeness of flame to liquid fuel

$\begin{array}{ll}\text { Greek } & \\ \Gamma & \text { circulation }\left(\mathrm{m}^{2} / \mathrm{s}\right) \\ v & \text { kinematic viscosity }\left(\mathrm{m}^{2} / \mathrm{s}\right) \\ \text { subscripts } \\ \mathrm{L} & \text { left } \\ \mathrm{R} & \text { right } \\ \text { AVE } & \text { average }\end{array}$

\section{INTRODUCTION}

A fire whirl may occur when a fire interacts with a spinning flow. In many cases, the spinning flow is generated by the upward buoyant flow from the fire. A particularly notable feature of fire whirl is its increased flame height compared with the original fire. An elongated flame is associated with increased heat flux to surrounding environment, potentially causing greater damage. In an extreme case, fire whirls killed 38,000 people in less than 15 min after the Kanto earthquake that struck the Tokyo area [1]. Soma and Saito [1] conducted a 1/100th scale-model experiment in order to understand the generation mechanism of the Kanto earthquake fire whirls. They succeeded in generating fire whirls in an open space that were similar to the Kanto earthquake fire whirls. Since their work, many studies on the generation mechanism of the Kanto earthquake and other fire whirls have been reported. These studies note that the fire whirls were often generated during forest and urban building fires [1-3].

A number of studies on fire whirl behavior have also been conducted, both theoretically [4-9] and experimentally $[4,6,10-13]$, with the aim of predicting the damages caused by fire whirls. In particular, studies of increased flame height have been extensively conducted. Kuwana et al. [4] both theoretically and experimentally studied the mechanism of the increase in flame height of laboratory-scale fire whirl. They derived the following equation of flame height by applying the Burke-Schumann theory [14].

FIRE SAFETY SCIENCE-PROCEEDINGS OF THE TENTH INTERNATIONAL SYMPOSIUM, pp. 671-680 


$$
\frac{z_{f}}{r_{p}}=\frac{P e}{4 \ln \left[1 /\left(1-Z_{s t}\right)\right]}
$$

This equation does not depend directly on the nature of flow, suggesting that the flame height increases because of an increase in burning rate of liquid fuel. This equation agreed reasonably well with the result of their laboratory-scale experiments. They considered that the increase of burning rate is due to the change in the shape of flame base based on experimental observations as well as theoretical considerations. With the presence of a spinning flow, the shape of the flame base changes and the flame approaches the liquid fuel, so that the heat transfer from flame to fuel is enhanced. This is why the evaporation of the liquid fuel is enhanced and the burning rate increases. This prediction of the flame height based on the burning rate is seen to be valuable in terms of the damage prediction of fire whirls. However, it will be more useful from the safety-management point of view to understand the relation between the flame height and vortex structure, and the mechanism of flame height increase in terms of the vortex structure, since the burning rate is not known a priori.

Recently, Chuah et al. [5] incorporated the spinning flow and heat-feed-back mechanism in the abovedescribed model and developed the Burke-Schumann-Burgers (BSB) model for small-scale fire whirls based on the assumption that vortex structures of fire whirls are able to be approximated by the Burgers vortex [15]. They derived the following relation between the flame height and the vortex structure.

$z_{f}=\left(z_{\text {foo }}^{2}+\text { const } \frac{r_{p}^{4}}{c^{2}}\right)^{1 / 2}$

This equation shows that the flame height is dependent on the core radius, $c$, a property of vortex flow.

This study aims at advancing the understanding of the mechanism of flame height increase, especially the relation between the flame height and the vortex structure. An objective of this study is to experimentally study the validity of Eq. 2, which has never been tested quantitatively. While Emmons and Ying [6] experimentally measured the flame height and circulation around a fire whirl with a temperaturecompensated thermistor probe, they did not consider the relation between flame height and vortex structure, and the flame-height increase due to an increase in the burning rate. In order to achieve our goals, we need to measure detailed velocity profiles around fire whirls, which is expected to be rather complicated. Hassan et al. [10] measured the flow around a fire whirl using the particle image velocimetry (PIV) technique, but it is stated in Ref. [10] that the accuracy of the measurement near the flame is limited because of experimental difficulties.

In this study, in order to experimentally understand the relation between the flame height and the vortex structure, and the mechanism of flame-height increase, we correlate the flame height and the shape of flame base, which affects the flame height, with the velocity profile around a fire whirl.

\section{EXPERIMENTAL METHODS}

\section{Fire Whirl Generator}

Figure 1 shows the experimental setup of the present fixed-frame-type fire whirl generator and instruments for velocity measurement. This experimental setting is similar to the one that Hassan et al. [10] used. Using a pair of split cylinders with axisymmetrically-placed slits, a spinning flow is generated by entrainment due to buoyant upward flow [11]. Flow field (vortex structure) and the flame heights vary with the slit distance and the cylinder diameter. In this study, we measured tangential and radial velocity distributions, and observed flame heights and the shapes of flame base under three different conditions (called conditions A, $\mathrm{B}$, and $\mathrm{C}$ ) in order to understand the relation between the flame height and the vortex structure. $19.4 \mathrm{~cm}$ diameter split cylinders were used under conditions A and B, whereas the cylinder diameter was $28.6 \mathrm{~cm}$ under condition C. Slit distance was $1.4,4.2$, and $13.4 \mathrm{~cm}$ under conditions A, B, and C, respectively. Methanol was chosen as fuel because it emits little soot and therefore the flow visualization can be conducted relatively easily. 


\section{Measurement of Velocity}

Tangential and radial velocity distributions were measured using a tracer method. A halogen lamp was used as a light source, and a convex lens and a light-blocking board were used for producing a light sheet. Tracer particles $(2.7 \mu \mathrm{m}$ silica particles) were seeded around a fire whirl for flow visualization. Particles were packed in a $3 \mathrm{~mm}$ diameter metal pipe; the pipe was then inserted near the flame, and particles were seeded from the pipe, enabling the flow visualization near the flame. Hassan et al. [10] reported that they could not capture particles near the flame in their PIV measurement, possibly because the vertical buoyant flow was so fast near the flame that most particles seeded from the slit (which was at a distance from the center) escaped from the region of observation before the particles approach the flame. In this study, on the contrary, many particles were directly seeded near the flame so that at least some particles could be captured. The exposure time of camera was set to be about 1/90-1/180 s, and the depth of irradiation region was set to be about $3 \mathrm{~cm}$.

Figure 2 shows typical photographs used for flow visualization. We first attempted to calculate both tangential and radial velocity profiles using the top images of Fig. 2. However, while reasonable distributions of tangential velocity were obtained, experimental errors were not negligible for radial velocity distribution. The errors are mainly caused by the fact that the radial velocity component is much smaller than the tangential component. To overcome this difficulty, a streamline was obtained using tracer smoke instead of silica particles (Fig. 2, bottom), yielding the change in radial distance during circulation, $\mathrm{d} r / \mathrm{d} \theta$. Using the separately measured tangential velocity (which is equal to $r \mathrm{~d} \theta / \mathrm{d} t$ ) and $\mathrm{d} r / \mathrm{d} \theta$, the radial velocity distribution was computed.

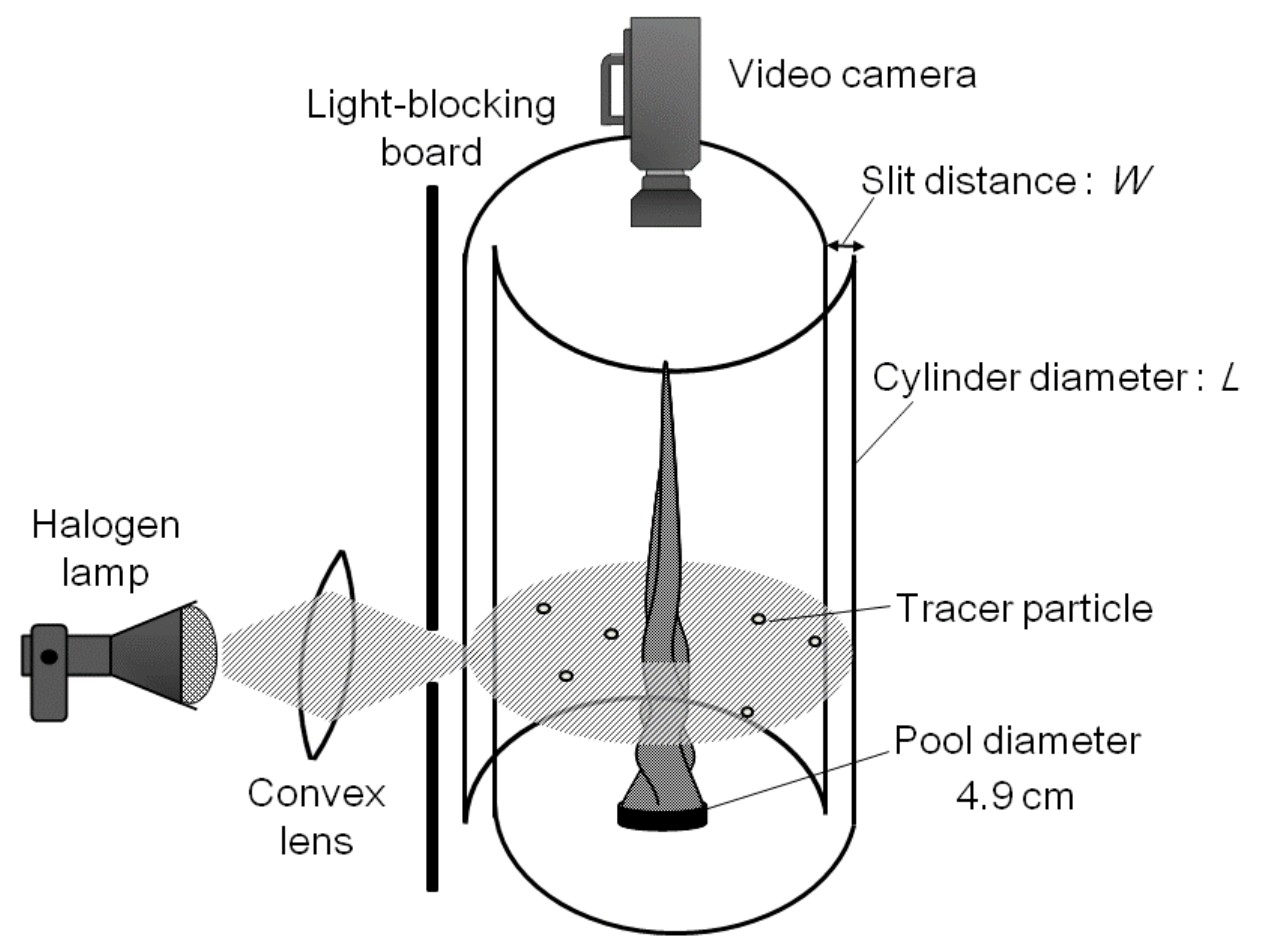

Fig. 1. A schematic of fixed-frame type fire whirl generator and instruments for measurement of velocity. 


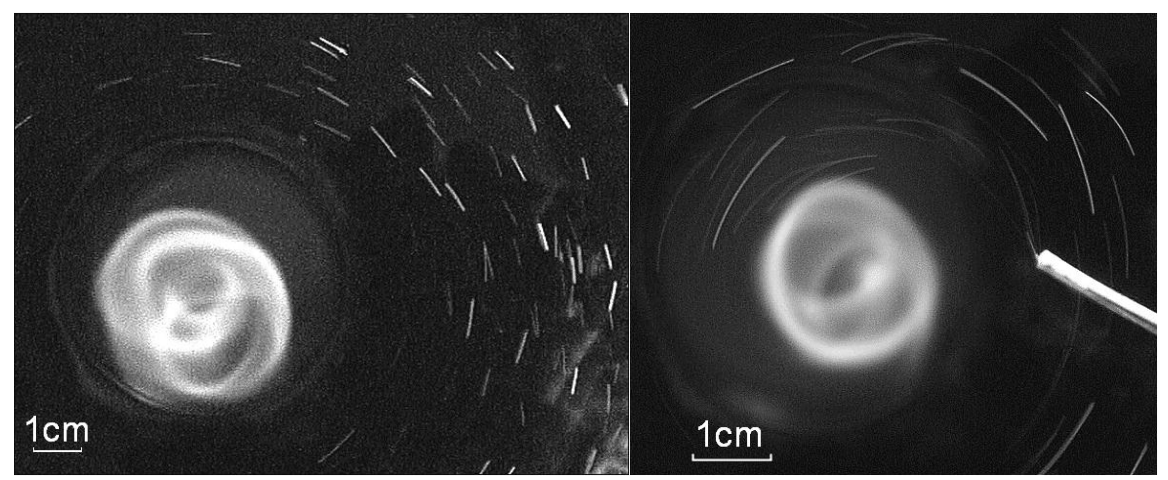

(a)

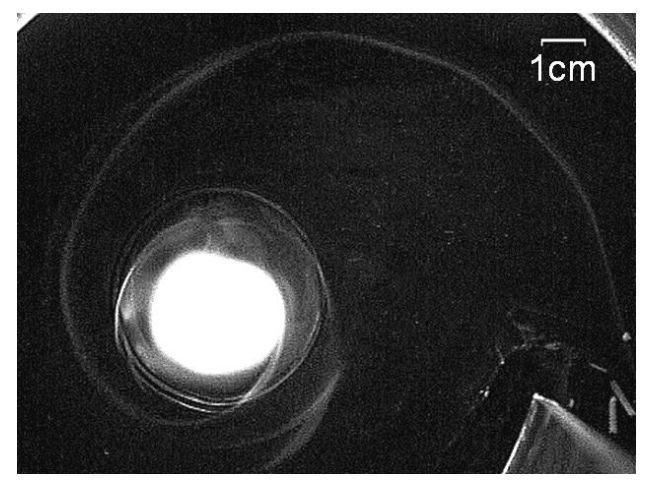

(b)

Fig. 2. Typical images used for flow visualization around fire whirl: (a) flow visualization for tangential velocity distribution using silica as tracer particles; (b) streamline obtained using tracer smoke.

\section{RESULTS AND DISCUSSION}

\section{Flame Height and Shape of Flame Base}

Figure 3 shows photographs of flame base under conditions A, B, C, and without spinning flow (hereinafter called condition D), and Fig. 4 shows the shape of the flame base analyzed using an image analysis software package (ImageJ). The measured flame height under each condition is: condition A, $31 \mathrm{~cm}$; B, $25 \mathrm{~cm} ; \mathrm{C}, 13 \mathrm{~cm}$; and D, $10 \mathrm{~cm}$, respectively. In order to quantify the shape of the flame base and understand the relation between the flame height and the shape of flame base, the shape of the flame base was approximated by the following equations respectively on left and right hand sides of image.

$$
z=a_{L} \cdot(r+L / 2)^{1 / 2}
$$

$$
z=a_{R} \cdot(r-L / 2)^{1 / 2}
$$

Here, $a_{\mathrm{L}}$ and $a_{\mathrm{R}}$ express the degree of closeness of the flame to liquid fuel; the smaller the value of $a$ is, the closer the flame is to the liquid fuel. The use of parabolic curve to approximate the flame-base shape is justified because the radial inflow dominates over the upward flow near the flame base; a parabolic flame shape is analytically obtained by adopting the Oseen approximation. By parameter fitting, $a_{\mathrm{L}}$ was obtained to be $0.10,0.17,0.33$, and 0.36 and $a_{\mathrm{R}}$ to be $0.17,0.14,0.29$, and 0.25 under conditions $\mathrm{A}, \mathrm{B}, \mathrm{C}$, and $\mathrm{D}$, respectively in Fig. 4. Figure 5 shows relation between the flame height and $a_{\mathrm{AVE}}$, the average of $a_{\mathrm{L}}$ and $a_{\mathrm{R}}$ over three different instances, indicating that $a_{\mathrm{AVE}}$ can be roughly correlated with the flame height, and the flame height increases with a decrease in $a_{\mathrm{AVE}}$ (or with the flame approaching the liquid fuel). 
In agreement with the analysis of Kuwana et al. [4], flame height increases as the flame approaches the liquid fuel and heat flux on fuel surface increases.

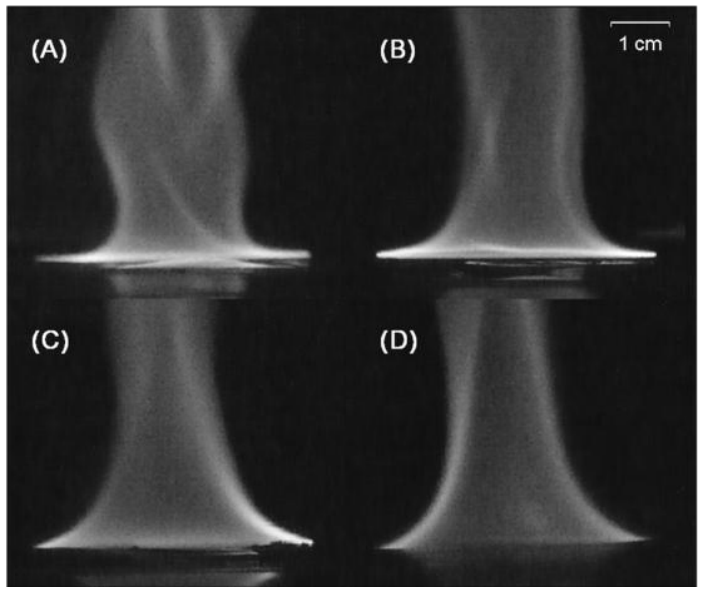

Fig. 3. Photograph of flame base under conditions A, B, C, and D.

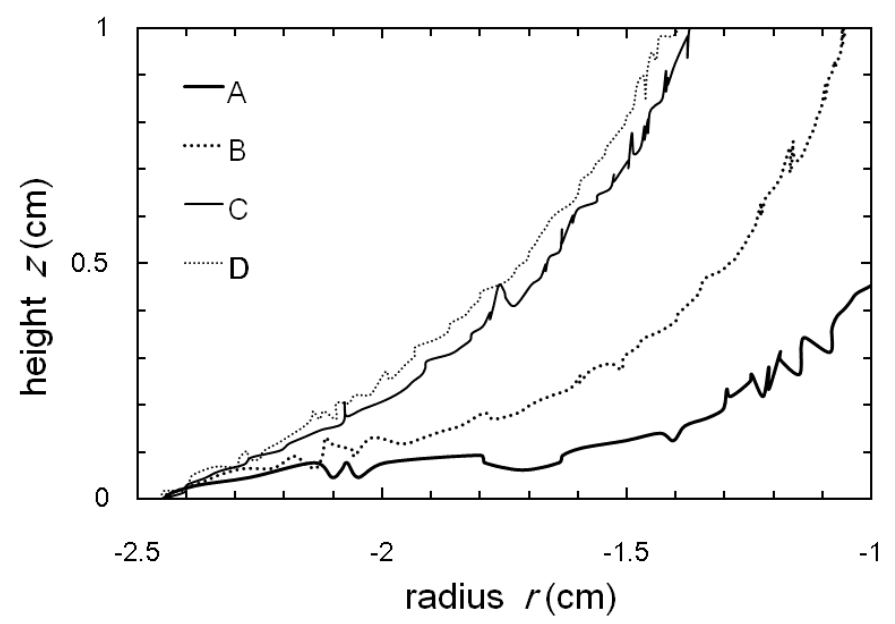

(a)

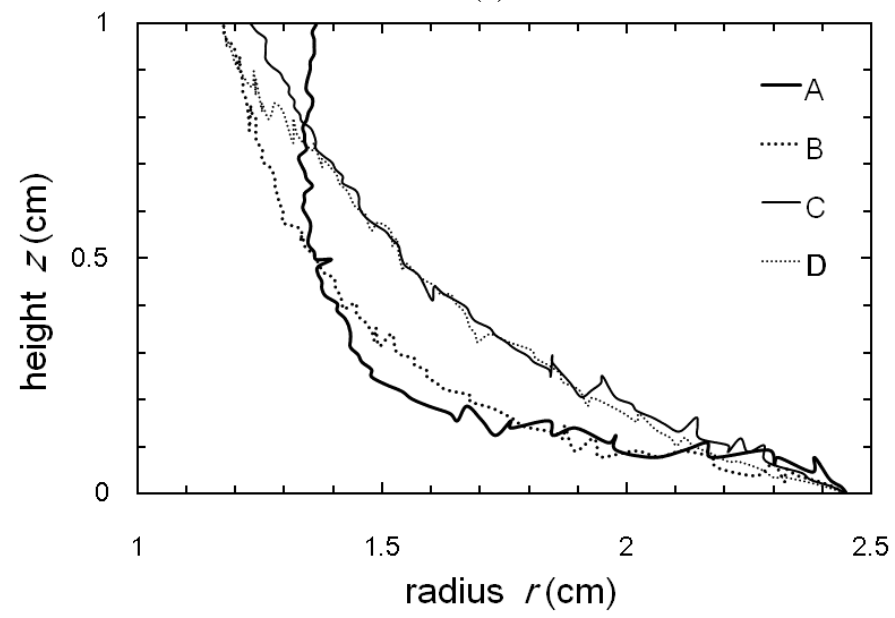

(b)

Fig. 4. Shape of flame base under conditions A, B, C, and D: (a) on left-; (b) right-hand sides of flame. 


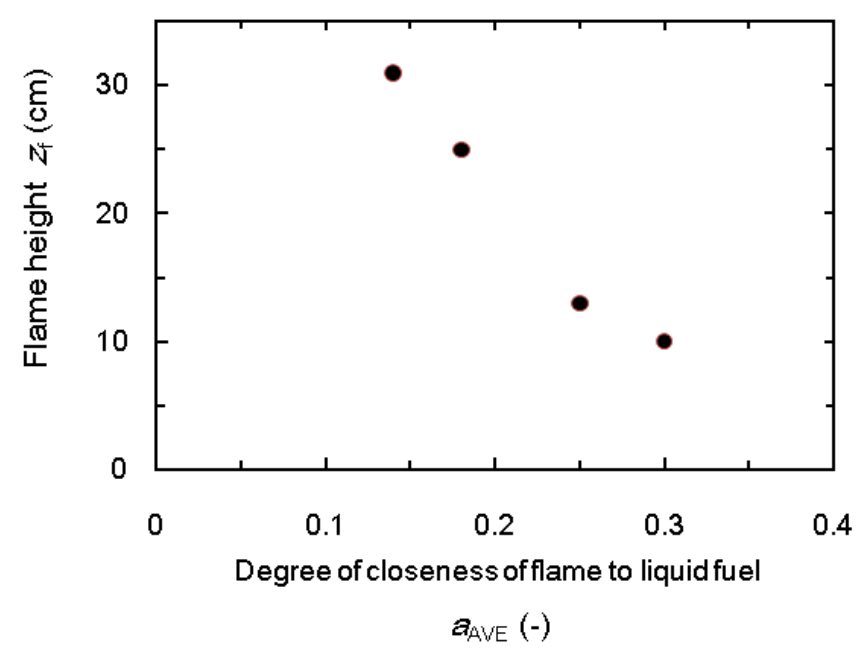

Fig. 5. Relation between the degree of closeness of flame to liquid fuel, $a_{\mathrm{AVE}}$, and the flame height.

\section{Velocity Profile}

Figure 6 shows the tangential and radial velocity distributions near the flame base $(2 \mathrm{~cm}$ from the liquid surface) under conditions A, B, and C. An approximate location of the visible flame is indicated by broken line. We see from the distribution of tangential velocity that the peak tangential velocity is fastest under condition A; conditions B and C follow in the decreasing order. Then, focusing on the core radius that Chuah et al. [5] suggested to be an important property determining the flame height (see Eq. 2), the core radius under condition $\mathrm{A}$ is largest; those under conditions $\mathrm{B}$ and $\mathrm{C}$ are nearly equal. Here, the core radius is the radius where the tangential velocity is maximal. Since the flame height is largest under condition A; and conditions $\mathrm{B}$ and $\mathrm{C}$ follow in the decreasing order $(31 \mathrm{~cm}, 25 \mathrm{~cm}$ and $13 \mathrm{~cm}$, respectively for conditions A, B and C), and this is an opposite result of theoretical analysis by Chuah et al. [5], it is likely that the core radius is not a key parameter that determines the flame height.

Next, the circulation is calculated by the tangential velocity distribution in radial distance range of greater than $4 \mathrm{~cm}$, because the tangential velocity profile is close to the free vortex in this range. The circulation under condition $\mathrm{A}$ is largest, and conditions $\mathrm{B}$ and $\mathrm{C}$ follow in descending order. This trend of circulation is similar to the flame heights and is in line with results of Emmons and Ying experiment [6]. Next, it is observed that the radial inflow velocities near the center under conditions A, B, and C are large and in descending order and follow the same trend as the flame height, suggesting that the radial velocity near flame base has a significant influence on the flame height. This is because the radial inflow makes the flame shape thinner resulting in a concave flame shape near the base which increases the heat flux to the liquid surface thereby increasing evaporation of the liquid fuel. The experimental observations of the importance of radial inflow in determining flame height are in agreement with the theoretical analysis by Kuwana et al. [4], which is a generalization of the analysis by Chuah et al. [5].

\section{Comparison to the Burgers Vortex}

The experimental observations presented above do not strongly support Eq. 2, which predicts that the flame height is determined by the core radius of vortex, indicating that the key assumption on which Eq. 2 is based, i.e., the assumption that the vortex around a fire whirl can be approximated by the Burgers vortex, may not be valid. To test the validity of the Burgers vortex assumption, we compared the measured velocity distributions with the Burgers vortex. The tangential and radial velocities of the Burgers vortex are given by Eqs. 5 and 6:

$v_{\theta}=\frac{\Gamma}{2 \pi r}\left[1-\exp \left(-\frac{r^{2}}{c^{2}}\right)\right]$ 


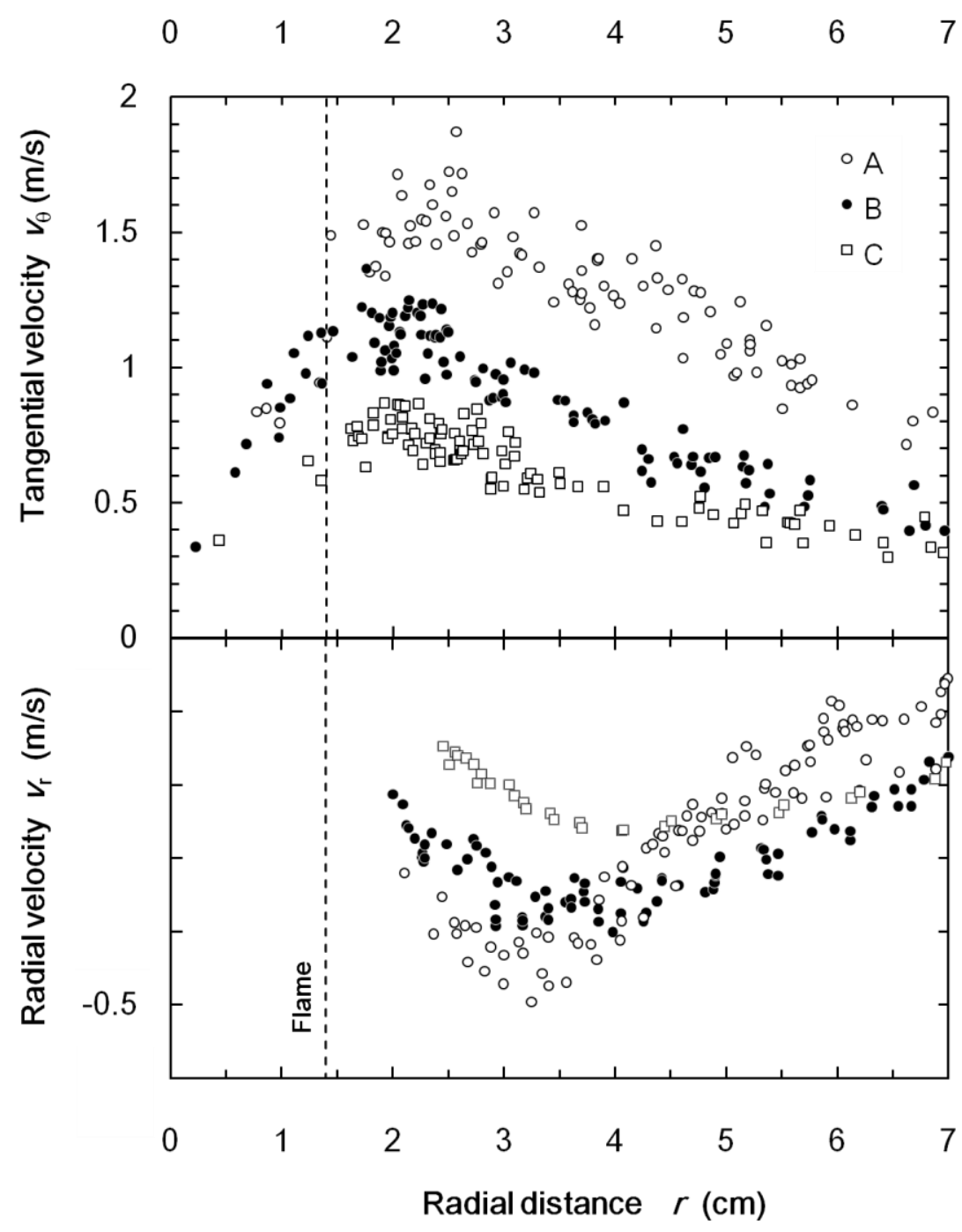

Fig. 6. Tangential and radial velocity distributions of a fixed-frame type fire whirl induced by a $4.9 \mathrm{~cm}$ diameter methanol pool-fire measured the using tracer method.

$v_{r}=-\frac{2 v}{c^{2}} r$

The solid line shown in Fig. 7 with measured tangential velocity data is the parameter-fitted curve of the Burgers vortex (Eq. 5). The distribution of the tangential velocity seems to be well approximated by the Burgers vortex, and the core radius is about $2.3 \mathrm{~cm}$. Next, we focus on the radial velocity. The solid line shown in Fig. 7 with measured radial velocity data is Eq. 6 with the core radius fitted in the range of $r<3 \mathrm{~cm}$. The core radius obtained by fitting radial velocity data was approximately $0.18 \mathrm{~cm}$, about $8 \%$ of that obtained by fitting tangential velocity data. These results indicate that the vortex around the fire whirl cannot be approximated by the Burgers vortex, probably because of the complexity of flow associated with density and temperature changes near the flame. Note that the values for average kinematic viscosity used in Eq. 6 were: air at room temperature, $1.80 \times 10^{-5} \mathrm{~m}^{2} / \mathrm{s}$ and methanol at $1000 \mathrm{~K}, 1.95 \times 10^{-5} \mathrm{~m}^{2} / \mathrm{s}$, although the choice of the value for kinematic viscosity does not qualitatively affect our conclusions. 


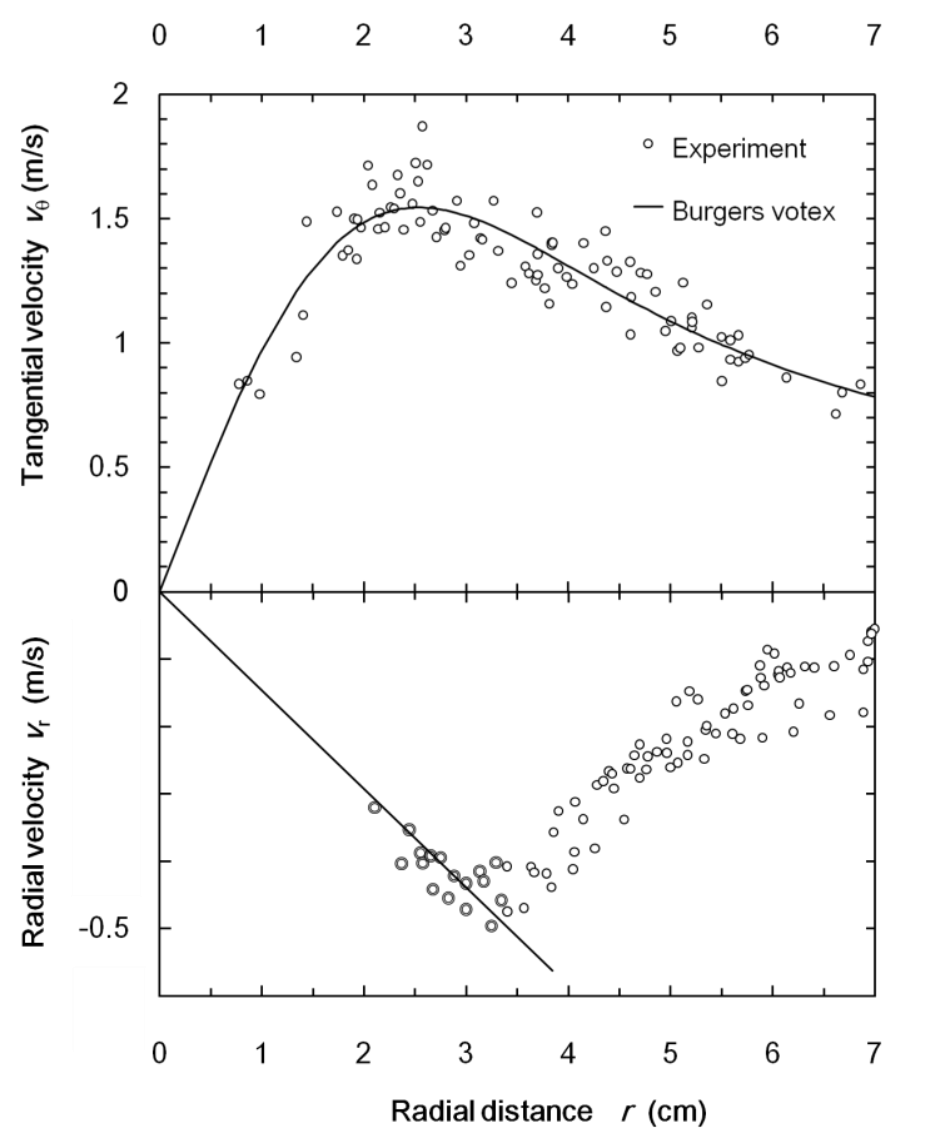

Fig. 7. Comparison of distribution of measured velocity and Burgers vortex under condition A.

\section{CONCLUSIONS}

Laboratory-scale fire-whirl experiments were conducted to study the mechanism of increase in flameheight in fire whirls. Flame height, flame-base shape, and tangential and radial velocity distributions near the flame base were measured. Fire whirls were generated under three different vortex conditions. The closeness of flame to the liquid surface was quantified by approximating the flame-base shape using a parabolic function. The flame height was found to be related with flame's closeness to liquid surface, validating previous theoretical analyses.

To test the validity of the Burgers-vortex assumption adopted in a previous study, it was attempted to approximate measured tangential and radial velocity data by a Burgers vortex. The core radius needed to reproduce tangential velocity data was found to be about ten times greater than that needed to reproduce radial velocity data, indicating that the Burgers vortex is not a good approximation of the vortex structure around a fire whirl. A further study is needed for better approximation of the vortex structure and for higher accuracy of prediction of the damage caused by fire whirls.

\section{ACKNOWLEDGMENT}

A part of this study was supported by the Promotion Program for Fire and Disaster Prevention Technologies, Fire and Disaster Management Agency, Japan.

\section{REFERENCES}

[1] Soma, S., Saito, K., (1991) Reconstruction of Fire Whirls Using Scale Models, Combustion and Flame 86: 269-284, http://dx.doi.org/10.1016/0010-2180(91)90107-M 
[2] Kuwana, K., Sekimoto, K., Saito, K., Williams, F.A., Hayashi, Y., Masuda, H., (2007) Can We Predict the Occurrence of Extreme Fire Whirls? AIAA Journal 45: 16-19, http://dx.doi.org/10.2514/1.28533

[3] Kuwana, K., Sekimoto, K., Saito, K., Williams, F.A., (2008) Scaling Fire Whirls, Fire Safety Journal 43: 252-257, http://dx.doi.org/10.1016/j.firesaf.2007.10.006

[4] Kuwana, K., Morishita, S., Dobashi, R., Chuah, K.H., Saito, K., (2011) The Burning rate's effect on the flame length of weak fire whirls, Proc. Combust. Inst. 33: 2425-2432, http://dx.doi.org/10.1016/j.proci.2010.05.049

[5] Chuah, K.H., Kuwana, K., Saito, K., (2009) Modeling a fire whirl generated over a 5-cm-diameter methanol pool fire, Combustion and Flame 156: 1828-1833, http://dx.doi.org/10.1016/j.combustflame.2009.06.010

[6] Emmons, H.W., and Ying, S.J., (1967) The Fire Whirl, Proc. Combust. Inst 11: 475-488, http://dx.doi.org/10.1016/S0082-0784(67)80172-3

[7] Battaglia, F., Rehm, R.G., and Baum, H.R., (2000) The Fluid Mechanics of Fire Whirls: An Inviscid Model, Physics of Fluids 12: 2859-2867, http://dx.doi.org/10.1063/1.1308510

[8] Byram, G.M., Martin, R.E., (1970) The Modeling of Fire Whirlwinds, Forest Science 16: 386-399.

[9] Muraszew, A., Fedele, J.B., Kuby, W.C., (1979) The Fire Whirl Phenomenon, Combustion and Flame 34: 29-45, http://dx.doi.org/10.1016/0010-2180(79)90077-4

[10] Hassan, M.I., Kuwana, K., Saito, K., Wang, F., (2005) Flow Structure of a Fixed-frame Type Fire Whirl, Fire Safety Science 8: 951-962, http://dx.doi.org/10.3801/IAFSS.FSS.8-951

[11] Saito, K., and Cremers, C.J., "Fire-whirl Enhanced Combustion,” Proc. Joint ASME/JSME Fluid Engineering Conference, Hilton Head, 1995.

[12] Satoh, K., and Yang, K.T., "Experimental Observations of Swirling Fires," ASME Heat Trans. Div., 335, 1996, pp. 393-400.

[13] Satoh, K., and Yang, K.T., (1997) Simulations of Swirling Fires Controlled by Channeled Selfgenerated Entrainment Flows, Fire Safety Science 5: 201-212, http://dx.doi.org/10.3801/IAFSS.FSS.5-201.

[14] Burke, S.P., Schumann, T.E.W., (1928) Diffusion Flames, Industrial and Engineering Chemistry 20: 998-1004, http://dx.doi.org/10.1021/ie50226a005

[15] Burgers, J.M., (1948) A Mathematical Model Illustrating the Theory of Turbulence, Advances in Applied Mechanics 1: 171-199, http://dx.doi.org/10.1016/S0065-2156(08)70100-5 